\title{
Life in Private Practice
}

\author{
Annette M. Chavez, MD, FAAFP, FAAHPM
}

(J Am Board Fam Med 2021;34:1035-1037.)

Keywords: Delivery of Health Care, Physicians, Policy, Primary Health Care, Quality of Health Care

When I was 40 years old, and 11 years into practice, I started to plot my premature retirement from medicine. The community hospital that had owned our practice released all employed physicians and later closed its doors. Our office joined a large multispecialty group with a coercive management style. Overhead increased dramatically. Doctors were threatened with pay reductions if productivity benchmarks were not met. Collection of insurance reimbursement was suboptimal, and the system favored doctors who saw very high volumes of patients. Physicians were expected to serve on several time-consuming committees. Our rent increased yearly, while our reimbursements decidedly did not. My 2 favorite partners quit the practice and moved to a small town. I was miserable.

When I was a resident, I was fond of saying that I would never own a practice or commercial real estate. Thirty-three years later, I am happy to say that I own both. I realized that the key to satisfaction in my profession and my life was autonomy and control. I gave this idea considerable thought before planning my escape from the large group practice. I have never regretted it.

I took a leap of faith in leaving the group practice because I was certain that I could run my own practice far better. I was warned that I would fail because physicians simply cannot understand the vagaries of running a practice. I respectfully disagreed, but unfortunately, too many physicians believe it. I certainly made mistakes along the way,

From the Carillon Family Practice, Dayton, OH (AMC). Conflict of interest: None.

Corresponding author: Annette M. Chavez, MD, FAAFP, FAAHPM, 2501 S. Dixie Dr. Kettering, OH 45409, Telephone: 937-643-3083, Fax: 937-643-3089 (E-mail: achavez676@aol.com).

\section{See Related Article on Page 1033.}

and my practice is not perfect, but I have managed to remain financially stable for 20 years.

I have colleagues who are employed by hospitalowned corporations and have a certain security but many added responsibilities. They must complete onerous quality assurance tasks, which in my opinion, do not add to meaningful patient care. They also spend significant time on evenings and weekends preparing electronic charts for the upcoming week. The online portal must be constantly monitored, and e-mails answered within a set period, even when the doctor is on vacation. There are strict rules for every aspect of the doctor's professional life, from the amount of time allotted to see patients to which holidays, weekends, and evenings the doctor is expected to work. Usually, the physician has no vote in who will be hired to work at the practice, whether as a medical assistant or a new physician. If there are personality incompatibilities, the physician is accused of failing to be a "team player."

When I decided to make my move, I first enlisted the full cooperation of my husband, who was an Air Force officer with an MBA. He had no medical background but took classes at the local community college to learn coding and medical terminology. While he was so engaged, I did my own credentialing, purchased malpractice, health, and disability insurance, engaged an attorney to incorporate the practice, and recruited staff. I read everything I could about starting a practice. We decided to build an office that would meet my specific requirements. Every examination room has a window. There are separate check-in and check-out areas to maintain ease of patient flow. There is a large lobby, nurses' station, lab, and staff break room. This building is situated on 1.3 acres of land, which we are transforming into an urban forest. We were able to pay off our mortgage in 13 years. 
In the early years of the practice, I had some associates but have been solo since then and do not use advanced practice professionals because I only want to be liable for myself. I find that a smaller office is easier to manage. When I first started, I hired only nurses but most aged into well-deserved retirement, and then I had problems replacing them. I decided to train premedical students from our local university to become certified medical assistants. They work a gap year until they go to medical school or some other pursuit. They train their replacements and over 4 years we have done well with this system. I also teach medical students in the office, so that naturally leads to a good mentoring relationship between the 2 sets of students.

I see the full spectrum of office-based family medicine, excluding obstetrics. I enjoy performing dermatologic procedures and joint injections. In the first 15 years of my practice life, I did hospital rounds but stopped when a nationwide transition to hospitalist care occurred. I miss inpatient care, but my call responsibilities are minimal in comparison, and life is much easier. I take 6 full weeks of vacation per year, mostly to stay home on our farm. I do not see patients on weekends or in the evenings. I work 3 full days in the office and 2 half days and schedule patients every 15 minutes. We do not have office meetings. If I need to notify the staff of anything, I tell them. I enjoy our staff and believe we have a collaborative relationship, with me at the helm of the ship.

A key to our success is the careful management of accounts receivables. My husband is responsible for all business dealings of the practice, including payroll, insurance collections, and managing the $401 \mathrm{~K}$. He is an expert at reimbursement and frequently advises me on how I can improve my coding. I know of colleagues who outsource all the collections and have rather substandard success with this. Having this "in-house" makes a definite impact on our financial viability.

We spend money wisely. I outfitted the entire office with finds from auctions, and I sewed examination room curtains for a fraction of their retail cost. We bought new technology when needed, such as our electrocardiogram (EKG), but I purchased other items such as otoscope heads on eBay. My Medical Assistants (MA's) shop the internet for the best deals on office supplies. My former registered nurse sewed patient gowns and lap sheets for us, and these are laundered rather than being discarded and replaced. The patients have liked them much better than the flimsy disposable gowns. We were able to alter some of those gowns into personal protective equipment for use during the pandemic.

We have never adopted an electronic medical record (EMR). We did not see the financial benefits of spending large amounts of money to buy and maintain a system. I have a colleague who likened paying for her EMR to sweeping large amounts of cash into a hole in the floor. We incurred some financial penalties for not fulfilling meaningful use criteria, but we came out ahead in the end.

I believe another secret to our success is hiring adequate numbers of staff. The premeds have worked out wonderfully as they are smart, motivated, and reliable. I have received feedback from medical school students about how valuable their experience was in my office. The patients love them as well. For my 1-doctor practice, I have $1 \mathrm{MA}$ work the phone and transmit the electronic prescriptions after my approval. Another works the floor rooming patients and doing whatever tasks are needed, such as venipuncture, shots, and EKGs. A third works the front desk with my full-time receptionist. The students rotate their position by half day. I have a part-time scheduler who also posts insurance checks into the system. A live person answers the phone as we do not have a phone menu or voice mail. We call patients with all test results. We do not have a formal mission statement or goals. We just try to deliver good medical care.

I have had friends who were not successful in independent practice for a few reasons. One suffered a serious embezzlement. Another spent too much money on 3 successive EMR systems. Another felt she could not afford to hire staff, so she only had 1 employee. When that person was absent, the doctor had no one to answer her phone. Yet another is marginally successful because he sees too few patients.

During the early days of the pandemic, our office visits diminished drastically. My husband has always been able to tell me how many patients I need to see just to meet our overhead. That number is currently between 10 and 12 patients a day. We were not meeting those goals during the state lockdown but recovered by June 2020 and ended the year on stable footing. I was stressed in the early days of the pandemic because I was not sure what protocols to enact in my office. But I had the freedom to decide 
how I would handle the situation and was able to maintain some income by instituting parking lot Coronavirus disease 2019 (COVID-19) testing. I knew of friends in corporate-owned practices who were not permitted to see any COVID-19 patients because all of them were referred to urgent care or the emergency department. We managed almost all COVID-19 patients ourselves except for a small number who were hospitalized. No staffer in my office contracted COVID-19 over the entire year, and we are now all immunized.

If done thoughtfully, independent private practice is fulfilling and enjoyable and meets a desperate need for qualified medical care for patients in any community. Now I am planning my retirement, but at an age where I feel I have paid my debt to society for educating me and allowing my slightly older husband to retire as well. In my days of unhappiness in my group practice, I could not wait to get out of clinical medicine. Now, I know how much I will miss my patients when I hang up my stethoscope. I am truly fortunate that I made that momentous life change when I had the opportunity. For physicians in less than ideal practice circumstances, I encourage them to consider it also. I know that the key to enjoying the practice of medicine is autonomy and financial independence. Our patients and families are the ultimate benefactors of our happiness.

To see this article online, please go to: http://jabfm.org/content/ 34/5/1035.full. 